\title{
Association Between Bruxism and Salivary Cortisol Levels: A Systematic Review
}

\author{
Asociación entre el Bruxismo y los Niveles de Cortisol Salival: Una Revisión Sistemática
}

Timilly Mayra Martins Cruz*; Saulo Gabriel Moreira Falci**; Endi Lanza Galvão***

CRUZ, T. M. M.; FALCI, S. G. M.; GALVÃO, E. L.Association between bruxism and salivary cortisol levels: A systematic review. Int. J. Odontostomat., 10(3):469-474, 2016.

ABSTRACT: The objective of this study was to verify the existence of an association between daytime and/or nighttime bruxism and the levels of cortisol in patients that carry this parafunction. A systematic review of observational studies were conducted in the following databases: PubMed; OVID and VHL (Virtual Health Library, LILACS, IBECS; MEDLINE and Scielo), until January of 2016 and without language restriction. An evaluation of titles and abstracts was conducted, followed by the full reading of the articles to determine which researches would be included. Observational studies that associated daytime and nighttime bruxism with salivary cortisol levels were included. Evaluation of the methodological quality was performed and extraction of data from the researches included. Two articles were included in this review. One of them showed moderate positive correlation between the BiteStrip scores and the levels of salivary cortisol in patients with bruxism. On the other hand, the other research demonstrated that children with sleep bruxism are more likely to have low levels of salivary cortisol. There is no conclusive evidence of association between bruxism and salivary cortisol.

KEY WORDS: bruxism; hydrocortisone; sleep bruxism; systematic review.

\section{INTRODUCTION}

Bruxism is defined as a non-functional activity or a parafunctional habit characterized by the unconscious repetitive motion of clenching and/or grinding of the teeth (Barbosa et al., 2008). There is no pre-defined age range, occurring in children, teenagers and adults where it may be manifested in two distinct forms. The most predominant form could occur when the patient is awake (daytime bruxism) or more commonly, during sleep (nocturnal bruxism), in which it can be considered a stereotyped and periodic motion disorder (Lavigne et al., 2003; Lavigne et al., 2003; Nekora-Azak et al., 2010; Bayardo et al., 1996).

The prevalence in children ranges from $7 \%$ to $15.1 \%$ (Lobbezoo et al., 2006), where girls are generally more affected. In adults, the values are estimated from $3.5 \%$ to $40.6 \%$, without difference between genres and decreasing with age (Bernhardt et al., 2004; Manfredini et al., 2013). Bruxism presents diverse etiological factors, such as local, psychological, systemic, occupational and genetic (Winocur et al., 2003; Sabuncuoglu et al., 2009). Secondary factors are also considered, such as medication, tobacco, alcohol, other drugs and the use of caffeine (Sabuncuoglu et al.; Gerber \& Lynd, 1998). Still, there are reports that this dysfunction may have a multifactorial origin, and that the cognitive and behavioral factors are the main predisposing factors of this disease (Gerber \& Lynd; Ferreira et al., 2015; Ferreira-Bacci et al., 2012).

The cognitive and behavioral factors, such as anxiety and stress, generate hormonal responses, probably due to stimulation of the hypothalamuspituitary-adrenal axis (Refulio et al., 2013). The product of this axis activation, the cortisol, which is secreted by the adrenal cortex, has its dispersion throughout all body fluids being detected in the urine, plasma and saliva (Kanegane et al., 2009). Described as a hormone

\footnotetext{
* MsC student, Department of Dentistry, Universidade Federal dos Vales do Jequitinhonha e Mucuri, Brazil.

* Departament of Dentistry, Universidade Federal dos Vales do Jequitinhonha e Mucuri, Brazil.

**** PhD student, Centro de Pesquisas René Rachou, Fundação Oswaldo Cruz, Brazil.
} 
related to stress, it is responsible for important processes in the human body, such as glucose production and activation of anti-stress and antiinflammatory processes (Guglielmoto et al., 2010; Hart \& Kamm, 2002; Hartley et al., 2012). Therefore, salivary cortisol has been reported as a possible anxiety, stress and depression indicator (Verdhara et al., 2003).

A systematic review aimed to verify the association between daytime bruxism, anxiety, stress, depression and personality characters. However, the scientificfindings were not sufficient to affirm that this association exists. Furthermore, this study did not have as the scope a specific association between bruxism and salivary cortisol levels (Manfredini \& Lobbezoo, 2009). Thus, the objective of the present systematic review was to verify the existence of scientific evidence of association between the daytime and/or nighttime bruxism and levels of salivary cortisol in patients that carries this parafunction.

\section{METHODOLOGY}

The study was conducted from electronic search in the databases: PubMed; OVID; VHL (Virtual Health Library- LILACS, IBECS, MEDLINE and Scielo). All eligible articles published until January of 2016, without language restrictions were included.

The following terms were used in the search strategy on Pubmed: ("hydrocortisone" "[MeSH Terms] OR "hydrocortisone"[All Fields] OR "cortisol"[All Fields]) AND ("bruxism"[MeSH Terms] OR "bruxism"[All Fields]) OR ("sleep bruxism"[MeSH Terms] OR ("sleep"[All Fields] AND "bruxism"[All Fields]) OR "sleep bruxism"[All Fields]). The terms used in the search strategy on OVID were: cortisol* OR hydrocortisone ${ }^{*}$ AND bruxism* OR sleep buxism*. The following terms were utilized in the search strategy on VHL: (cortisol AND bruxism OR sleep bruxism).

In order to identify some article not found in the databases, a search was conducted in the references of the articles included in the review.

Inclusion and Exclusion Criteria. The inclusion criteria were observational studies with human beings, which evaluated the relation of daytime and nighttime bruxism with levels of salivary cortisol. To be included, the studies had to measure the salivary cortisol levels and its association in patients diagnosed with bruxism.
The exclusion criteria of this study were. Case reports, technical notes, animal studies, in vitro studies, abstracts, textbooks, dissertations, opinion articles, review articles and studies that did not find the level of salivary cortisol.

Studies Selection. The articles selection underwent a careful and independent evaluation from two authors. First, a reading of titles and abstracts from all databases found articles was performed. The articles not related to the subject were excluded in this phase. Those articles that generated doubt and those which appeared to fulfill all inclusion criteria, were accessed and read entirely. During the reading of such articles, those that did not contemplate the inclusion criteria were excluded from this review. The studies that met the inclusion criteria were included in the data extraction and qualitative analysis.

Study quality evaluation. The studies' quality evaluation was performed using the New CastleOttawa Scale (NOS) for cross-sectional studies modified by Herzog et al. (2013). This scale comprised the selection, comparison and results domains, in which the selection domain could reach a maximum of five stars, the comparison domain could reach a maximum of two stars, and the results domain a maximum of three stars. Therefore, the studies could reach a maximum of ten stars, in which eight stars or more represented a low risk of bias; between seven and six stars, represented moderate risk of bias, and five stars or lower considered a high risk of bias.

Data extraction. The following data, when available in the studies, were included in the final analysis of the selected articles: author, publication year, country, study design, sample size and characteristics, age, bruxism diagnoses method, salivary cortisol evaluation method, bruxism type, time of salivary sample collection, statistics tests utilized and results.

\section{RESULTS}

The studies selection is diagramed in Figure 1. The search resulted in 1424 articles, in which 768 were from PUBMED, 647 from OVID and 9 from VHL. After the duplicates removal, the total found articles were 1297. For full reading, 10 articles were accessed, in which 8 articles were excluded for not meeting the eligibility criteria. During the manual search in the references lists, additional articles were not found. 


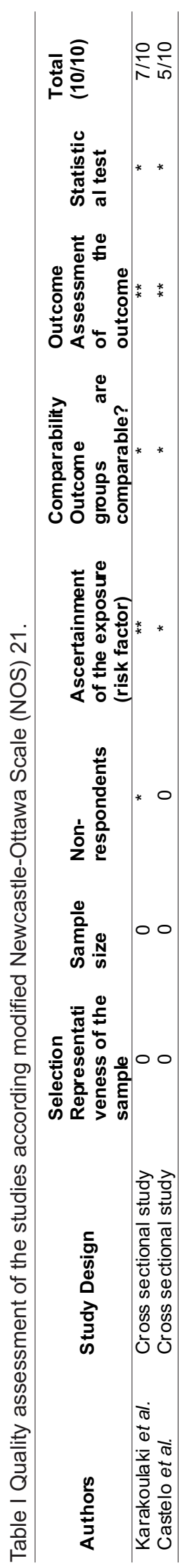

Therefore, two publications were included in this review.

One of the two articles, Karakoulaki et al. (2015), was a cross-sectional study with 45 adults (20 men and 25 women) held in Greece. The participants age in this study ranged from 25 to 52 years. As the diagnoses method, questionnaires and an Electromyography (EMG-Bite Strip) were used. The bruxism type evaluated was the nighttime bruxism, and the saliva collection timings were immediately after waking up and between 7 and 9 o'clock in the morning. This study's result showed higher salivary cortisol levels in patients with bruxism than in those without bruxism $(p<0.001)$. There was still a positive correlation between the BiteStrip scores in patients with bruxism and their salivary cortisol level $(r=0.401, p=0.047)$.

The second article, Castelo et al. (2012), was also a cross-sectional study. However, 100 children with nighttime bruxism and 27 children without bruxism were evaluated, in Brazil. The age of the participants in this study ranged from 6-8 years and the bruxism diagnoses method was application of questionnaires to the caregivers/siblings about the sounds of teeth grinding besides the clinical exam. The evaluation method for salivary cortisol quantity was through immune-enzymatic assay. The salivary cortisol levels were evaluated when the patient was still lying in bed after 30 minutes of waking up. This study's results showed that children with sleep bruxism are more likely to have lower concentrations of salivary cortisol (OR: 0.882: $\mathrm{Cl}=0.74-0.98)$.
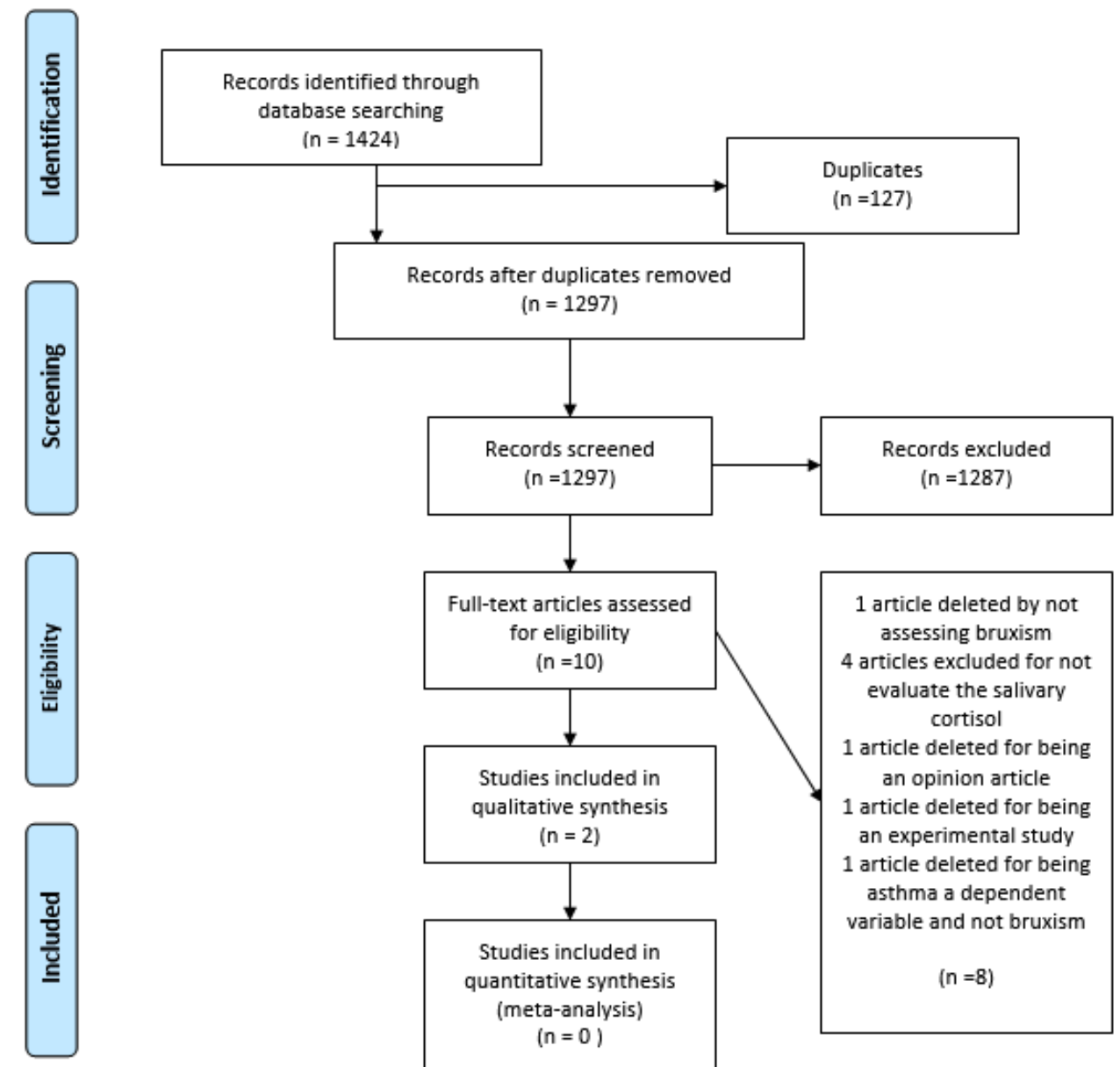

Fig. 1. Studies screening. 
The methodology's quality and consistency were considered moderate for the study by Karakoulaki et al. (2015), while the study by Castelo et al. (2010), presented low methodology's quality. Both studies showed flaws in sample size, compromising the score in the selection domain. Table 1 illustrates the quality evaluation of the selected studies (Table I).

\section{DISCUSSION}

The present systematic review aimed to verify the existence of an association between daytime and/ or nighttime bruxism and the salivary cortisol levels in adults and children. According to the judgment of the studies quality, moderate to high risk of bias was observed in these studies. The great methodological differences found between the studies, such as the type of design, the scenarios where the researches took place, the studied groups variables and characteristics definitions, explains the findings of this research. Due to the high heterogeneity among studies and the large methodological differences between them, it was not possible to perform meta-analysis, which shows that this subject should be explored in further research.

Bruxism consists of stereotyped movements characterized by teeth clenching and grinding and may occur during the day or night. The literature converges in a multifactorial etiology for this behavior, however, there are hypothesis that anxiety and stress are primary factors for bruxism development (Kampe et al., 1997; Vanderas et al., 1999). Currently, the saliva sample collection for investigation of cortisol presence, a biomarker for stress, has been widely applied, mainly because it is a non-invasive, secure and simple method (Refulio et al.; Verdhara et al.; Karakoulaki et al.; Castelo et al.; Amato et al., 2015; Tahara et al., 2007). Thus, as the cortisol level and bruxism are both related to stress (Karakoulaki et al.), it was expected that there were studies associating these two variables. However, few studies were found in the present review.

This review's studies did not show a standardization related to the hour and repetition of sample collection. The circadian rhythm and stress are known factors for regulation of salivary cortisol secretion, controlled by the circadian oscillator located in the suprachiasmatic nucleus. This hormone shows higher levels in the morning and lower levels at dusk, implying directly in the hormonal levels evaluation (Matsuda et al., 2012). In order to eliminate the variability caused by the circadian cycle, it is recommended that the salivary collections be held more times during the day. In the included studies, the collection was held when waking up (Karakoulaki et al.) and after thirty minutes. In his study, Karakoulaki et al. (2015), collected insufficient quantities of salivary samples. Greater quantities of saliva samples from each participant provide more reliable results, eliminating the variability caused by the circadian cycle.

Investigations about the association between bruxism and stress provided contradictory results (Karakoulaki et al.; Tahara et al.; Lobbezoo \& Naeije, 2001; Ahlberg et al, 2002; Pierce et al, 1995), which may be attributed to bruxism's multifactorial nature, different stress evaluation methods, different types of biomarkers present in the saliva related to stress, and furthermore, due to the divergence of stress definition as a risk or etiological factor (Karakoulaki et al.). Karakoukali et al., evaluated the relationship between bruxism characteristic movements and stress by measuring salivary cortisol levels in adults. According to these authors, it is suggested that a relation exists between bruxism, high levels of salivary cortisol and stress perception as it was found by Winocur et al. (2011) and Hicks \& Conti (1991). However, a study done by Nakata et al. (2008), where the relation between workplace stress and bruxism was evaluated in a sample of Japanese factory workers, found a weak association between these variables in men. The results from the studies by Karakoulaki et al., may not be representative of bruxism severity, as this variable was evaluated only one night of a random week day.

Pediatric bruxism is still poorly monitored due to lack of knowledge and consistent scientific evidence about the risk factors, pathophysiology, and their consequences. Apparently, pediatric bruxism is not associated with high salivary cortisol levels, as expected. Castelo et al. (2012), evaluated the response of salivary cortisol levels when awaking, in children with sleep bruxism, and concluded that these children demonstrated low hormone levels in the saliva. On the other hand, Amato et al. (2015), found presence of sleep bruxism and a high salivary cortisol level associated with asthmatic children. However, this study did not verify a direct association between bruxism and salivary cortisol levels.

The results of this systematic review should be interpreted with caution due to methodological differences and limitations of the selected studies. First, the tests for salivary cortisol should be standardized and interpreted based on values obtained in the laboratory 
using samples from normal controls of the population, with different age groups and genders. Another aspect to highlight concerns the design of the studies included in this review. In cross-sectional studies exposure and outcome measures are taken at the same time. The key issue in this type of design is the inability to know whether exposure (salivary cortisol) precedes or is a consequence of the health condition (bruxism).

\section{CONCLUSION}

This systematic review did not show conclusive scientific evidence between the salivary cortisol levels and bruxism. The small articles quantity that addresses the subject and the lack of methodological standardization suggests a need for new studies.

CRUZ, T. M. M.; FALCI, S. G. M.; GALVÃO, E. L. Asociación entre el bruxismo y los niveles de cortisol salival: Una revisión sistemática. Int. J. Odontostomat., 10(3):469-474, 2016.

RESUMEN: El objetivo de este estudio fue verificar la existencia de la asociación entre el bruxismo diurno y/o de la noche y los niveles de cortisol salival en pacientes con esta parafunciones. Una revisión sistemática de los estudios de observación se realizaron en las siguientes bases de datos: PubMed; OVID y VHL (Virtual Health Library - LILACS, IBECS, MEDLINE y Scielo) hasta enero de 2016, sin restricciones de idioma. Se llevó a cabo la evaluación de los títulos y resúmenes, seguido de la lectura completa de los artículos, para determinar qué trabajos estarían incluidos. Se incluyeron estudios de observación asociando los niveles de cortisol salival y bruxismo diurno y nocturno. Se llevó a cabo la evaluación de la calidad metodológica y la extracción de datos de los estudios incluidos. Dos artículos fueron incluidos en esta revisión. Uno de ellos mostró correlación positiva moderada entre los scores de BiteStrip en pacientes con niveles de cortisol salival y bruxismo. Mientras que otro mostró que los niños con bruxismo del sueño son más propenso a tener bajos niveles de cortisol en la saliva. No hay evidencia concluyente de la asociación de bruxismo y cortisol salival.

PALABRAS CLAVE: bruxismo, cortisol salival, bruxismo del sueño, revisión sistemática.

\section{REFERENCES}

Ahlberg, J.; Rantala, M.; Savolainen, A.; Suvinen, T.; Nissinen, M.; Sarna, S.; Lindholm, H.; Könönen, M. Reported bruxism and stress experience. Community Dent. Oral Epidemiol., 30(6):405-8, 2002.

Amato, J.N.; Tuon, R.A.; Castelo, P.M.; Gavião, M.B.D.; Barbosa, T.S. Assessment of sleep bruxism, orthodontic treatment need, orofacial dysfunctions and salivar biomarkers in asthmatic children. Arc. Oral Biol., 60(5):698-705, 2015.

Barbosa, T.S.; Miyakoda, L.S.; Pocztaruk, Rde L.; Rocha, C.P.; Gavião, M.B. Temporomandibular disorders and bruxism in childhood and adolescence: Review of the literature. Int. J. Pediatr. Otorhinolaryngol., 72(3):299-314, 2008.

Bayardo, R.E.; Mejia, JJ.; Orozco, S.; Montoya, K. Etiology of oral habits. ASDC J. Dent. Child., 63(5):350-3, 1996

Bernhardt, O.; Gesch, D.; Splieth, C. et al. Risk factors for high occlusal wear scores in a population-based sample: results of the Study of Health in Pomerania (SHIP). Int. J. Prosthodont., 17(3):333-9, 2004.

Castelo, P. M..; Barbosa, T. de S.; Pereira, L. J.; Fonseca, F. L.; Gavião, M. B. Awakening salivar cortisol levels of children with sleep bruxism. Clin. Biochem., 45(9):6514, 2012.
Ferreira, N. M.; dos Santos, J. F.; dos Santos, M. B.; Marchini, L. Sleep bruxism associated with obstructive sleep apenea syndrome in children. Cranio., 33(4):251-5, 2015.

Ferreira-Bacci, A.V.; Cardoso, C.L.; Días-Serrano, K.V. Behavioral Problems and Emotional Stress in Children with Bruxism. Braz.Dent. J., 23(3):246-51, 2012.

Gerber, P.E.; Lynd, L.D. Selective serotonin-reuptake inhibitor-induced movement disorders. Ann. Pharmacother., 32(6):692-8, 1998.

Guglielmotto, M.; Giliberto, L.; Tamagno, E.; Tabaton, M. Oxidative stress mediates the pathogenic effect of different Alzheimer's disease risk factors. Front Aging Neurosci., 2:3, 2010

Hart, A.; Kamm, M.A. Review article: mechanisms of initiation and perpetuation of gut inflammation by stress. Aliment. Pharmacol. Ther., 16(12):2017-28, 2002.

Hartley, T.A.; Knox, S.S.; Fekedulegn, D.; Barbosa-Leiker, C.; Violanti, J.M.; Andrew, M.E. et al. Association between depressive symptoms and metabolic syndrome in police officers:results from two cross-sectional studies. J. Environ. Public Health, 2012. doi.10.1155 / 2012/861219

Herzog R, Álvarez-Pasquin MJ, Díaz C, Del Barrio JL, Estrada JM, Gil Á. Are healthcare workers' intentions to 
vaccinate related to their knowledge, beliefs and attitudes? A systematic review. BMC Public Health., 2013; 19;13:154.

Hicks, R.A.; Conti, P. Nocturnal bruxism and self-reports of stress-related symptoms. Percept Mot Skills. 1991; 72(3 Pt 2):1182.

Karakoulaki, S.; Tortopidis, D.; Andreadis, D.; Koidis, P. Relationship between sleep bruxism and stress determined by saliva biomarkers. Int. J. Prosthodont., 2015;28(5):467-74.

Kampe, T.; Edman, G.; Bader, G.; Tagdae, T.; Karlsson, S. Personality traits in a group of subjects with long-standing bruxing behavior. J. Oral Rehabil., 24(8):588-93, 1997.

Lavigne, G.L.; Kato, T.; Kolta, A.; Sessle, B.J. Neurobiological mechanisms involved in sleep bruxism. Crit. Rev. Oral Biol. Med., 14:30-46, 2003.

Lobbezoo, F.; Van Der Zaag, J.; Naeije, M. Bruxism: its multiple causes and its effects on dental implants - an updated review. J. Oral Rehabil., 33(4):293-300, 2006.

Lobbezoo, F.; Naeije, M. Bruxism is mainly regulated centrally, not peripherally. J. Oral Rehabil., 28(12):1085-91, 2001.

Manfredini, D.; Lobbezoo, F. Role of psychosocial factors in the etiology of bruxism. J. Orofac. Pain, 23(2):153-166, 2009 .

Manfredini, D.; Winocur, E.; Guarda-Nardini, L.; Paesani, D.; Lobbezoo, F. Epidemiology of bruxism in adults: a systematic review of the literature. J. Orofac. Pain. 27(2):99-110, 2013.

Matsuda, S.; Yamaguchi, T.; Okada, K.; Gotouda, A.; Mikami, S. Day-to-day variations in salivary cortisol measurements. J. Prosthodont. Res., 56(1):37-41, 2012.

Nakata, A.; Takahashi, M.; Ikeda, T.; Hojou, M.; Araki, S. Perceived psychosocial job stress and sleep bruxism among male and female workers. Community Dent Oral Epidemiol., 36(3):201-9, 2008.

Nekora-Azak, A.; Yengin, E.; Evlioglu, G.; Ceyhan, A.; Ocak, O.; Issever, H. Prevalence of bruxism awareness in Istanbul, Turkey. Cranio, 28(2):122-127, 2010.

Pierce, C.J.; Chrisman, K.; Bennett, M.E.; Close, J.M. Stress, anticipatory stress, and psychologic measures related to sleep bruxism. J. Orofac Pain, 9(1):51-6, 1995.

Refulio, Z.; Rocafuerte, M.; De la Rosa, M.; Mendoza, G.; Chambrone, L. Association among stress, salivary cortisol levels and chronic periodontitis. J. Periodontal Implant Sci., 2013; 43:96-100.

474
Tahara, Y.; Sakurai, K.; Ando, T. Influence of chewing and clenching on salivary cortisol levels as an indicator of stress. J. Prosthodont., 16(2):129-35, 2007.

Vanderas, A.P.; Menenakou, M.; Kouimtzis, T.; Papagiannoulis, L. Urinary catecholamine levels and bruxism in children. J. Oral Rehabil., 26(2):103-10, 1999.

Vedhara, K.; Miles, J.; Bennett, P.; Plummer, S.;Tallon, D.; Brooks, E. et al. An investigation into the relationship between salivary cortisol, stress, anxiety and depression. Bio. Psychol., 62(2):89-96, 2003.

Winocur, E.; Gavish, A.; Voikovitch, M.; Emodi-Perlman, A.; Eli, I. Drugs and bruxism: a critical review. J. Orofac. Pain., 17(2):99-111, 2003.

Winocur, E.; Uziel, N.; Lisha, T.; Goldsmith, C.; Eli I. Selfreported bruxism-associations with perceived stress, motivation for control, dental anxiety and gagging. J. Oral Rehabil., 38(1):3-11, 2011.

Correspondence to:

Timilly Mayra Martins Cruz

Rua da Glória, 187

Sala 12 - Campus I

Programa de Pós-Graduação em Odontologia

Universidade Federal dos Vales do Jequitinhonha e Mucuri Diamantina, Minas Gerais

BRAZIL

E-mail: timillycruz@gmail.com

Received: 03-06-2016

Accepted: 26-09-2016 